\title{
A Bibliometric Mapping of Educational Technology in Indonesia (2011-2020)
}

\author{
Darmawansah \\ National Taiwan University of Science and Technology, Taipei, Taiwan
}

\begin{abstract}
This study reveals educational technology research trends in Indonesia for the consecutive ten years (2011-2020). The analysis included co-authorship, co-occurrence, citation, and co-citation by finding the top authors, universities, journals, the most used keywords, and citation variables. The data was taken from the Web of Science. A total of 248 studies were found and then shrunk into 59 studies related to educational technology. The mapping analysis used VOSviewer to visualize the selected studies. It was concluded that the Nurkhamid had the highest numbers of citations, while publications from Yogyakarta State University were declared as the most-cited papers. In terms of the most-cited journals (citation analysis), the Australasian Journal of Educational Technology was named on it, and Computers \& Education was the most-cited based on co-citation analysis. Based on the cooccurrence analysis, some of the terms, including education, technology, activity theory, English, and science, were enunciated as the most used keywords in the selected period. Further analysis was discussed herein.
\end{abstract}

\section{CONTACT}

darmawansahlavoe@gmail.com

\section{KEYWORDS}

Educational technology, research trends, bibliometric mapping, bibliometric analysis, Indonesia

\section{INTRODUCTION}

Technology has played a pivotal role in the education field, and its usage becomes exponential in various approaches such as distance education, learning simulation, educational games, and hands-on education [1]. The long history of technology in education has been wide-ranging from the pre-digital age to the current $\mathrm{e}-\mathrm{and} \mathrm{m}$ learning [2]. In Indonesia, studies on the development of learning tools have significantly grown as Coronavirus19 (COVID-19) hit the nation and switched conventional learning into virtual learning. These studies explored innovated-technology aids to assist learners facing the emergence of online classes such as; augmented reality [3], virtual learning [4], and automated questions [5]. However, this particular research has never been discussed in the systematic review studies. Therefore, the attention to collect the current literature and present them in the review study is our primary goal.

To provide educational technology research trends in Indonesia, I adopted the bibliometric mapping analysis to perform our review systematically. The following research questions were investigated through bibliometric mapping analysis on educational technology in Indonesia from 2011 to 2020.

1. Who are the most cited Indonesian authors on educational technology research in Indonesia from 2011 to 2020 ?

2. What are the most-cited Indonesian universities on educational technology research in Indonesia from 2011 to 2020?

3. What are the most-used keywords and the most-used terms in the abstract section on educational technology research in Indonesia from 2011 to 2020?

4. What are the most-cited (citation and co-citation) journals publishing research on educational technology research in Indonesia from 2011 to 2020?

\section{METHODS}

The data was retrieved and collected from the Web of Science (WOS) as our sole database. I chose WOS due to the high quality of studies included in its database, as recommended by Fu and Hwang [6]. It was supported by prior studies that argued that WOS is a reliable source and a highly qualified publications provider [7, 8]. Also, this study referred to the PRISMA approach [9] to report our analysis systematically. This study searched the literature using Boolean expression. I applied the keywords "education," "instruction," "learning," "teaching," "teacher," "learner," "internet," "computer," technology, and "research" [10]. The keywords were input to the WOS database by limiting the years search to ten years (2011-2020). I limited the research categories to "education educational research," "scientific education disciplines," and "psychology educational." "Article" and "Indonesia" were opted to the only document type and country on the filter results. The index was SSCI and SCIE. There were 248 articles collected as a result. 
For further analyses, I selected only the articles focusing on three main concerns: educational studies, technology use, and experimental studies, resulting in the selection of 59 articles as the final data used for this study.

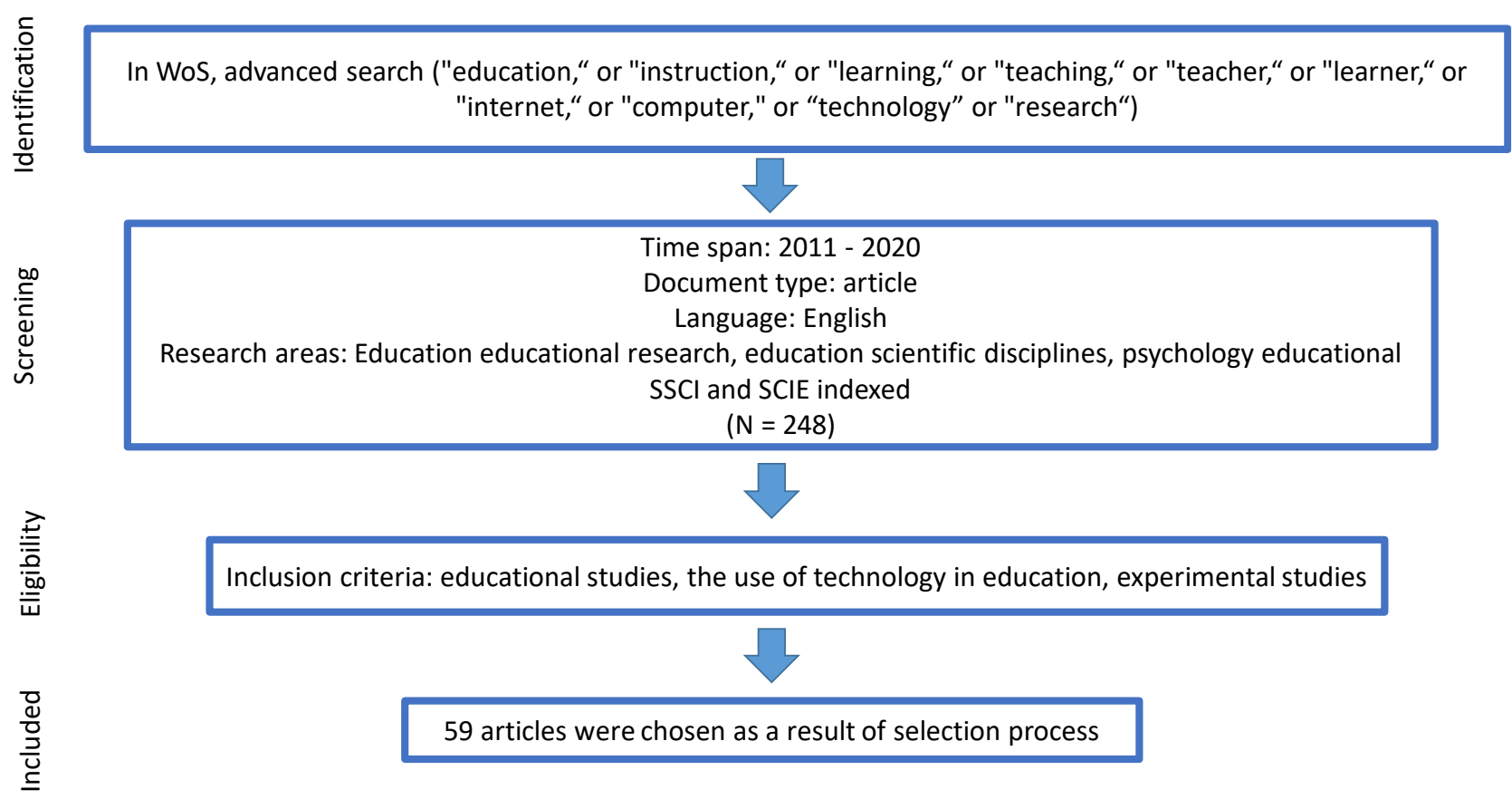

Figure 1. The searching procedure based on PRISMA

I adopted bibliometric mapping to bring interactive visualization in showing scientific information [11]. The analysis measured which Indonesian authors, institutions, and publications have impacted Indonesia's educational technology-related research. In addition, The corpus analyses through bibliometric mapping were executed to show the most used keywords and words on the selected articles. The VOSviewer software was employed to visualize the networks of all research questions by using citation, co-citation, co-occurrences analysis. The 59 selected publication is shown in Figure 1. Although the first three years $(2011$ - 2013) were steady, with only two publications per year, the graph shows a significant peak in the last two years $(2019-2020)$. It can be concluded that the publication of educational technology studies in Indonesia during the COVID-19 pandemic was a fifty percent increase compared to the pre-pandemic year. 


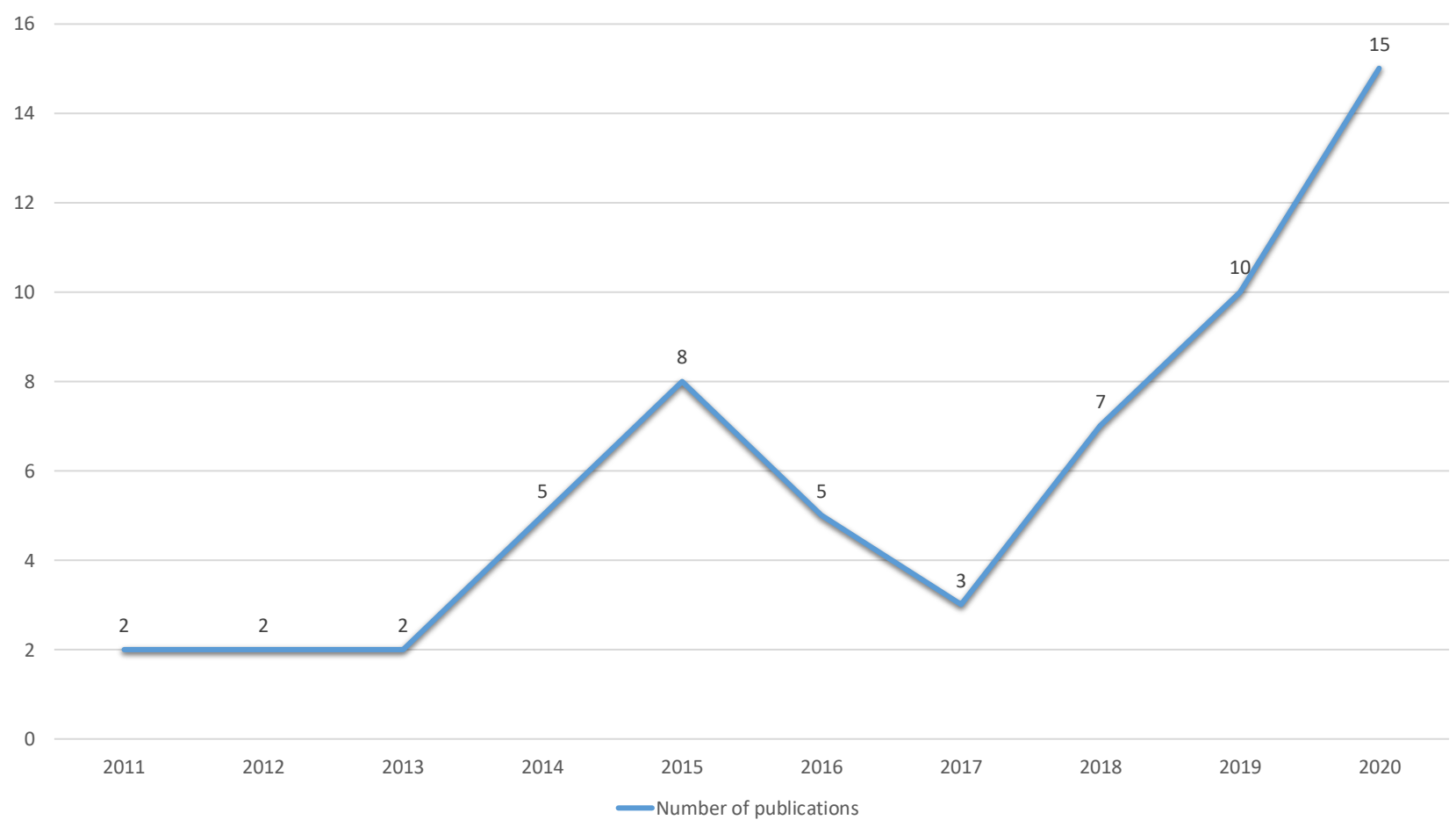

Figure 1. Publication distribution of educational technology in Indonesia from 2011 to 2020

\section{RESULTS AND DISCUSSIONS}

\section{Most-cited Indonesian authors in educational technology research}

The citation analysis was set to investigate the most cited Indonesian authors in educational technology research. The minimum number of documents was set to two, and the number of citations was set to one. Six authors automatically met the thresholds (Table 1). Nurkhamid from Yogyakarta State University received the highest number of citations among Indonesian authors. His articles are the most cited work in educational technology research in the last ten years, followed by Marwan Ardi and Saputra Andrian as the second and third most-cited Indonesian authors, respectively.

Table 1. Indonesian authors ranked by the number of citations.

\begin{tabular}{llcc}
\hline \multicolumn{1}{c}{ Authors } & \multicolumn{1}{c}{ Affiliation } & Citation & Documents \\
\hline Nurkhamid & Yogyakarta State University & 20 & 3 \\
Marwan, Ardi & Politeknik Negeri Pontianak & 12 & 2 \\
Saputra, Andrian & Universitas Lampung & 10 & 2 \\
Drajati, Nur Arifah & UNS Surakarta & 7 & 3 \\
Degeng, I Nyoman Sudana & State University of Malang & 7 & 2 \\
Permanasari, Adhistya Erna & Universitas Gadjah Mada & 3 & 1 \\
\hline
\end{tabular}

\section{Most-cited Indonesian universities in educational technology research}

The citation analysis was employed to investigate Indonesian universities with the highest citation numbers in educational technology research. The minimum number of the document was set two, while the number of citations was set three. There were 14 out of 87 universities that met the thresholds. The result is shown in Figure 2. It is concluded that Yogyakarta State University is the most-cited Indonesian university in educational technology research, with five documents and 32 citations in total. Universitas Indonesia $(28,5)$ and Universitas Jember $(20$, 2) become the second and third most-cited Indonesian universities in our findings. 


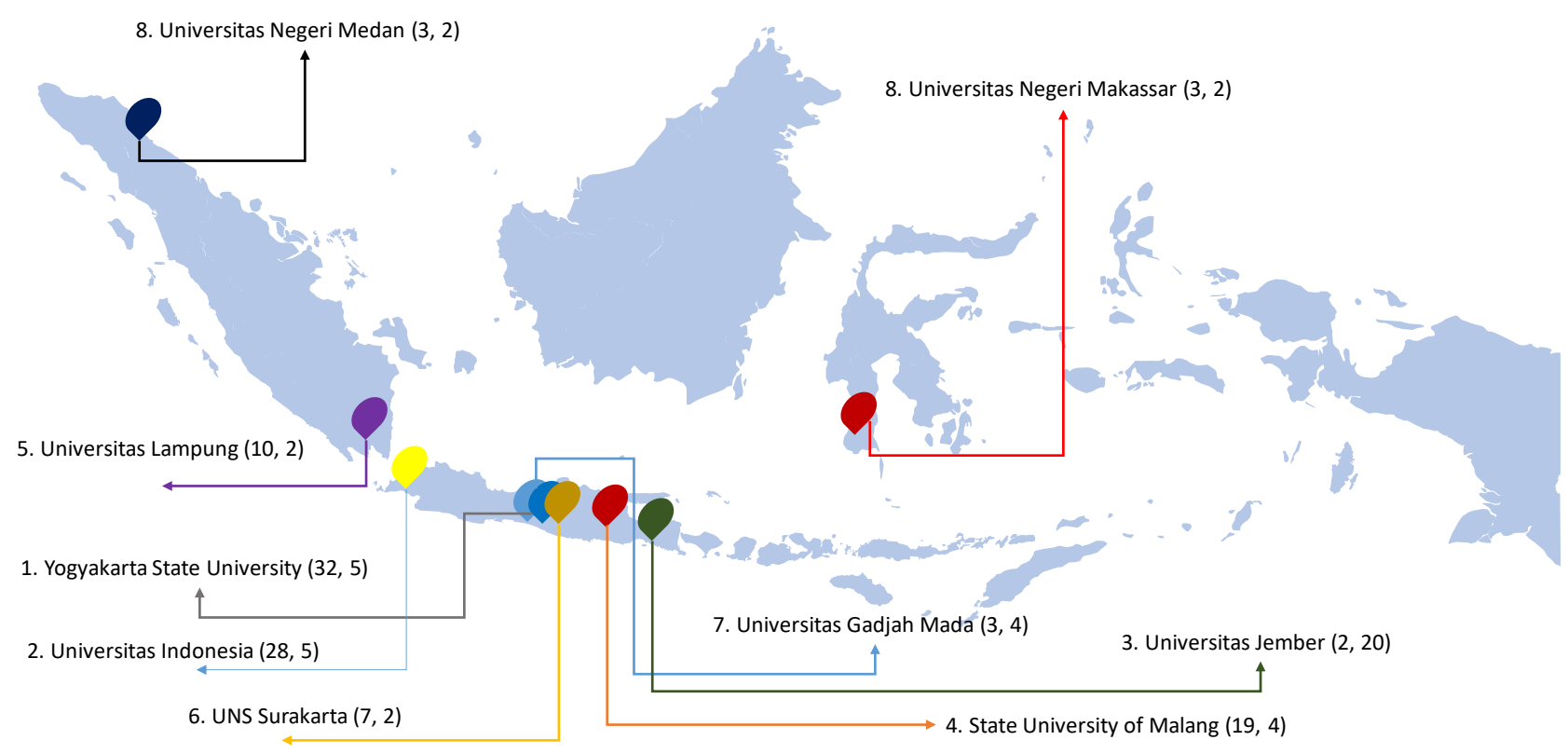

Figure 2. Indonesian universities ranked by the number of citations (ranks, university's names, citations, documents)

\section{Most-used keywords on educational technology research}

The co-occurrence analysis was employed by selecting all keywords, while the minimum number of keywords was set to two. 58 out of 354 keywords were met the threshold. The result was shown in Figure 3 . There are seven clusters found, which are represented by different colors. The more extensive link which keyword has means the bigger network it has. Thus, education is the most used keyword in the selected articles, with the number of cooccurrences is nine, and the total link strength is 28 . Technology $(7,23)$ became the second most-used keywords, while activity theory $(3,16)$, English $(5,16)$, and Science $(3,16)$ stood on the third, fourth, and fifth most-used keywords, respectively.

\section{Most-used terms in educational technology research's abstracts}

The abstract of selected studies was uploaded into the software. The abstract and full counting method was selected to analyze the most-used words. The minimum number of occurrences was set as six. There were 55 out of the 1543 terms that met the threshold. From each of the 55 terms, a relevance score was calculated. The most relevant terms were selected. As a result, the number of terms to be selected automatically is 33 . Based on figure 4 shown, "activity" was the most-used term in educational technology research's abstracts with 32 occurrences. It is followed by "use" (26), "group" (24), "data" (21), "factor" (21), and "medium" (20). 


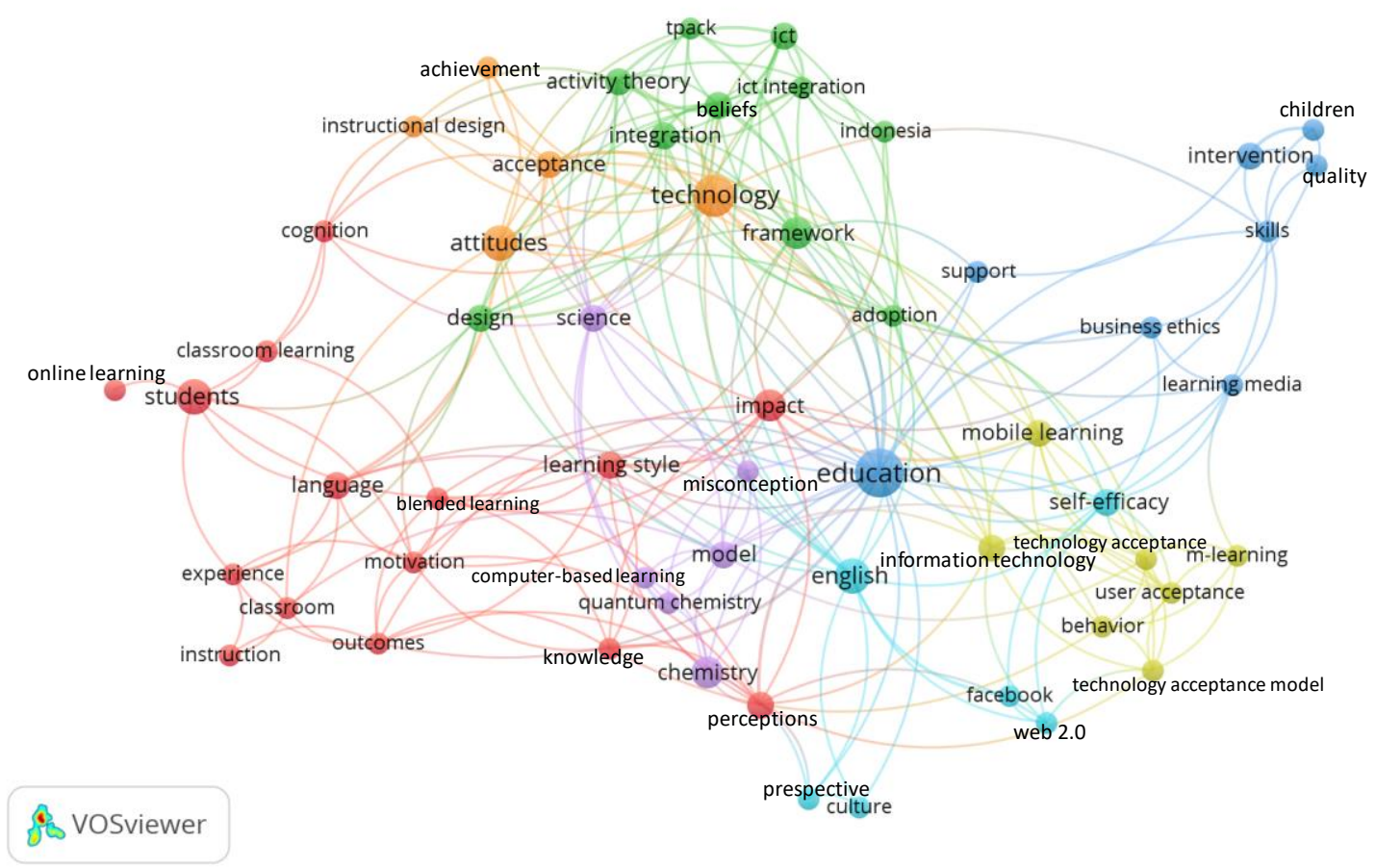

Figure 3. The most used keywords on educational technology research in Indonesia

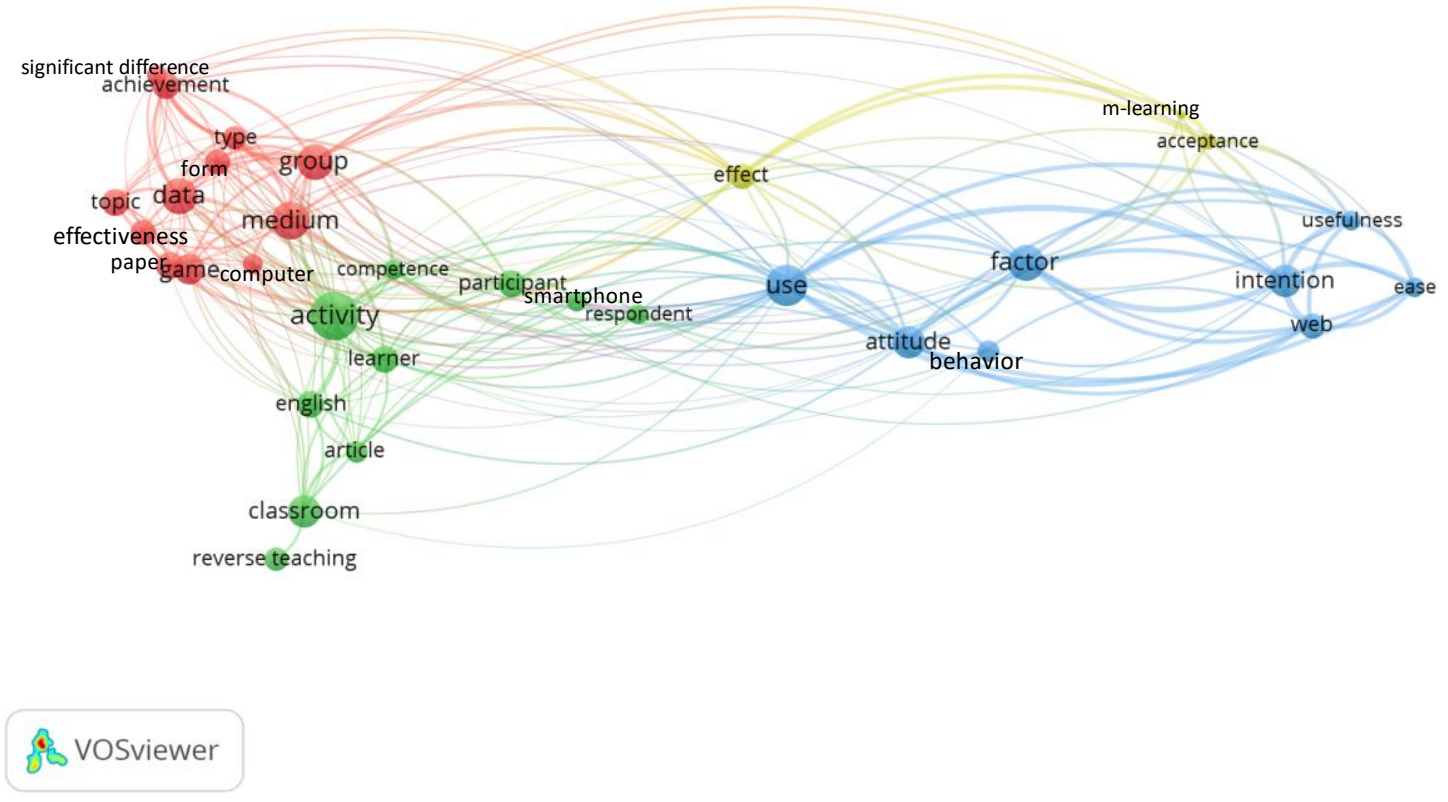

Figure 4. Four clusters and the most-used words in abstracts

\section{Most cited journals (citation and co-citation) on educational technology research}

The citation analysis was selected to explore the relationship between the publication and citations. The number of documents was set two, while the total citation was also set two. The number of sources was automatically given as seven. As table 2 shows, the Australian Journal of Educational Technology (54 citations, three publications) was 
declared the most-cited journal. The second most-cited journal was Eurasia Journal of Mathematics Science and Technology Education (49 citations, five publications). The third most-cited journal was the Journal of Baltic Science Education (43 citations, seven publications).

In addition, the co-citation analysis was selected. The minimum number of documents was set to 19, and six out of 1397 sources were met the threshold. Table 3 displays the result, which shows Computers \& Education (59 co-citations) is the most-cited journal. The second most-used journal is Computers in Human Behavior (49 cocitations). At the same time, the British Journal of Educational Technology, Procedia Social Behavior, System, and International Journal of Science and Education shared position as the third most-cited journals with 19 cocitations.

Table 2. Most cited journals (citation analysis)

\begin{tabular}{lcc}
\hline Journals & f & Citations \\
\hline Australasian Journal of Educational Technology & 3 & 54 \\
Eurasia Journal of Mathematics Science and Technology Education & 5 & 49 \\
Journal of Baltic Science Education & 7 & 43 \\
International Review of Research on Open and Distributed Learning & 3 & 28 \\
Computer Assisted Language Learning & 2 & 9 \\
Education and Information Technologies & 11 & 4 \\
Distance Education & 1 & 2 \\
\hline
\end{tabular}

Table 3. Most cited journals (co-citation analysis)

\begin{tabular}{lc}
\hline Journals & Citations \\
\hline Computers \& Education & 59 \\
Computers in Human Behavior & 49 \\
British Journal of Educational Technology & 19 \\
Procedia Social Behavior & 19 \\
System & 19 \\
International Journal of Science and Education & 19 \\
\hline
\end{tabular}

\section{CONCLUSIONS}

This review study revealed the research trends on educational technology research in Indonesia for ten consecutive years. This study used bibliometric mapping analysis due to its construction and low-dimensional visualizations. Besides, Bibliometric mapping provides each term's position in ways that the distance among any relationships reflects their similarities [7]. Also, the matric collections of each co-occurring offer visualization of research trends [12]. The first findings of the bibliometric mapping showed that the most cited Indonesian author in educational technology research is Nurkhamid, whose studies were mainly cited in the last ten years (2011-2020). These studies were focused on technology-assisted authentic learning [13], incidental and incremental learning [14], and active learning [15]. In addition, Yogyakarta State University was declared as the most-cited Indonesian university in educational technology research led by five publications in SSCI/SCIE indexed. Authors from Yogyakarta State University recently published studies in the application of advanced technologies in education such as virtual reality [4], augmented reality [3], and MOOC [16].

To some extent, although the finding revealed numbers of publications in every Indonesian university, it is still considered lower in number compared to other emerging countries in Asia (e.g., Taiwan, Korea, and Singapore. For instance, Indonesia's neighbor country, Singapore, has much higher productivity in publishing educational technology studies. It is due to Singapore Government's vision to allocate more budget for research and international publication [2]. In comparison, Indonesia Government is suggested to provide more research capacity building to boost research output across institutions [17]

In other results, the most cited journals were Australasian Journal of Educational Technology (citation analysis) and Computers \& Education (co-citation analysis). These two journals were considered reputable journals on technology-assisted education [18]. Their current impact factors validate it in Journal Citation Reports 2020 (JCR), which are 3,067 (Australasian Journal of Educational Technology), and 8,538 (Computers \& Education), respectively.

The other significant findings in our bibliometric mapping analysis are involved in the extraction process of articles' keywords and abstracts. The purposes of investigating both keywords and words in the abstract section are to seek authors' overview of the articles and a comprehensive summary of the studies [19]. The six most-used keywords in the selected studies were "education," "technology," "activity theory," "English," and "Science." At the same time, the three most used terms in the abstract were "use," "group," and "data.". These findings summarize that most educational technology studies in Indonesia aimed to investigate technology in either English 
language learning or Science learning. In other words, the research focus is limited only to examine the use of technology in English and Science learning. Therefore, it is suggested to broaden the investigation through other subject learnings such as Social Science, Arts, special education studies, and integrated learning (STEM and STEAM)

In addition, the investigations possibly conducted the quasi-experiment in which two or more groups of learners were randomly assigned any treatments. The goal of the investigation was mainly focused on confirming particular learning activities' theories on the use of technology by collecting quantitative and or qualitative data, whereas designing and employing innovated technologies and learning strategies were rarely to be found. Thus, it is strongly recommended to extend educational technology research into empirical studies which empowering advanced technology through learning strategies based on educational theories.

This review study provides research directions of educational technology research in Indonesia in the past ten years. When examining the top Indonesian authors and universities in the educational technology field, I found that most publications were collaborative research between international institutions and Indonesian institutions. The international institutions identified through selected studies are predominantly located in Taiwan [13-15, 20], Hong Kong [21-24], Australia [25-27], and China [28, 29]. In addition, the number of Indonesian publications in SSCI and SCIE indexed is still limited compared to other emerging countries. Thus, it is urgently suggested that Indonesian scholars and practitioners fill this gap by doing collaborative research with international scholars.

Several limitations of this study are discussed herein. First, the use of more than one database might bring more comprehensive findings than rely on a sole database only. Therefore, other scholars are encouraged to expand this limit to see any overall results. Second, bibliometric mapping is limited to examine the title, keywords, and abstract. Third, the period was only chosen for ten years respectively. It could have brought a whole picture of Indonesia's educational technology research trends if the period were extended. Considering the analysis of content could display a wide range of investigations on technology in education for Indonesia. By conducting content analysis, the study could review; what type of technology is used in Indonesia, what extend the learning intervention affects the learners, and more insightful information that Indonesian scholars and practitioners can use as references.

\section{REFERENCES}

[1] Kucuk S, Aydemir M, Yildirim G, et al. Educational technology research trends in Turkey from 1990 to 2011. Comput Educ 2013; 68: 42-50.

[2] Jung I, Yoo M. An analysis of Asia-Pacific educational technology research published internationally in 2000-2013. Asia Pacific Educ Rev 2014; 15: 355-365.

[3] Sari RC, Sholihin M, Yuniarti N, et al. Does behavior simulation based on augmented reality improve moral imagination? Educ Inf Technol 2021; 26: 441-463.

[4] Sholihin M, Sari RC, Yuniarti N, et al. A new way of teaching business ethics: The evaluation of virtual reality-based learning media. Int J Manag Educ 2020; 18: 100428.

[5] Wijanarko BD, Heryadi Y, Toba H, et al. Question generation model based on key-phrase, context-free grammar, and Bloom's taxonomy. Educ Inf Technol 2021; 26: 2207-2223.

[6] Fu Q-K, Hwang G-J. Trends in mobile technology-supported collaborative learning: A systematic review of journal publications from 2007 to 2016. Comput Educ 2018; 119: 129-143.

[7] Chen M-RA, Hwang G-J, Majumdar R, et al. Research trends in the use of E-books in English as a foreign language (EFL) education from 2011 to 2020: a bibliometric and content analysis. Interact Learn Environ 2021; $1-17$.

[8] Shukla AK, Janmaijaya M, Abraham A, et al. Engineering applications of artificial intelligence: A bibliometric analysis of 30 years (1988-2018). Eng Appl Artif Intell 2019; 85: 517-532.

[9] Moher D, Liberati A, Tetzlaff J, et al. Preferred Reporting Items for Systematic Reviews and MetaAnalyses: The PRISMA Statement. PLoS Med 2009; 6: e1000097.

[10] Kucuk S, Aydemir M, Yildirim G, et al. Educational technology research trends in Turkey from 1990 to 2011. Comput Educ 2013; 68: 42-50.

[11] Pinto M, Fernández-Pascual R, Caballero-Mariscal D, et al. Information literacy trends in higher education (2006-2019): visualizing the emerging field of mobile information literacy. Scientometrics 2020; 124: 1479-1510.

[12] Bashir F, Warraich NF. Systematic literature review of Semantic Web for distance learning. Interact Learn Environ 2020; 1-17.

[13] Chen G-D, Nurkhamid, Wang C-Y, et al. Digital Learning Playground: supporting authentic learning experiences in the classroom. Interact Learn Environ 2013; 21: 172-183. 
[14] Dang T-D, Chen G-D, Dang G, et al. RoLo: A dictionary interface that minimizes extraneous cognitive load of lookup and supports incidental and incremental learning of vocabulary. Comput Educ 2013; 61: 251-260.

[15] Chen G-D, Nurkhamid, Wang C-Y, et al. Self-Observation Model Employing an Instinctive Interface for Classroom Active Learning. Educ Technol Soc 2014; 17: 14-26.

[16] Bonk CJ, Zhu M, Kim M, et al. Pushing Toward a More Personalized MOOC: Exploring Instructor Selected Activities, Resources, and Technologies for MOOC Design and Implementation. International Review of Research in Open and Distributed Learning. Int Rev Res Open Distrib Learn; 19, https://www.erudit.org/en/journals/irrodl/2018-v19-n4-irrodl04233/1055530ar.pdf (2018).

[17] Smith P. Distance and blended learning in Asia. Distance Educ 2010; 31: 127-128.

[18] Arici F, Yildirim P, Caliklar Ş, et al. Research trends in the use of augmented reality in science education: Content and bibliometric mapping analysis. Comput Educ. Epub ahead of print 2019. DOI: 10.1016/j.compedu.2019.103647.

[19] Nadzar NMAM, Bakri A, Ibrahim R. A bibliometric mapping of malaysian publication using co-word analysis. Int J Adv Soft Comput its Appl 2017; 9: 90-113.

[20] Kuo B, Daud M, Mathematics CY-EJ of, et al. Multidimensional computerized adaptive testing for Indonesia junior high school biology. ejmste.com, https://www.ejmste.com/article/multidimensionalcomputerized-adaptive-testing-for-indonesia-junior-high-school-biology-4423 (accessed 3 May 2021).

[21] Lim CP, Juliana, Liang M. An activity theory approach toward teacher professional development at scale (TPD@Scale): A case study of a teacher learning center in Indonesia. Asia Pacific Educ Rev 2020; 21: 525538.

[22] Lee JS, Drajati NA. Willingness to communicate in digital and non-digital EFL contexts: scale development and psychometric testing. Comput Assist Lang Learn 2020; 33: 688-707.

[23] Lee JS, Drajati NA. English as an international language beyond the ELT classroom. academic.oup.com. DOI: $10.1093 /$ elt/ccz018.

[24] Lee JS, Drajati NA. Affective variables and informal digital learning of English: Keys to willingness to communicate in a second language. Australas J Educ Technol. Epub ahead of print 1 April 2019. DOI: 10.14742/ajet.5177.

[25] Marwan A, Sweeney T. Using Activity Theory to Analyse Contradictions in English Teachers' Technology Integration. Asia-Pacific Educ Res 2019; 28: 115-125.

[26] Thompson K, Carvalho L, Aditomo A, et al. The synthesis approach to analysing educational design dataset: Application of three scaffolds to a learning by design task for postgraduate education students. $\mathrm{Br}$ J Educ Technol 2015; 46: 1020-1027.

[27] Boucheix J-M, Lowe RK, Putri DK, et al. Cueing animations: Dynamic signaling aids information extraction and comprehension. Learn Instr 2013; 25: 71-84.

[28] Ramdani JM, Widodo HP. Student teachers' engagement in Facebook-assisted peer assessment in an initial teacher education context: speaking 2.0. J Educ Teach 2019; 45: 348-352.

[29] Kusumaningputri R, Widodo HP. Promoting Indonesian university students' critical intercultural awareness in tertiary EAL classrooms: The use of digital photograph-mediated intercultural tasks. System 2018; 72: 49-61. 